\title{
VISÕES DE MEIO AMBIENTE E SUAS IMPLICAÇÕES PEDAGÓGICAS NO ENSINO DE QUÍMICA NA ESCOLA MÉDIA
}

Carlos Alberto Marques*, Fábio Peres Gonçalves, Eduardo Zampiron, Juliana Cardoso Coelho, Ligia Catarina Mello, Paulo Roberto Silva Oliveira e Renata Hernandez Lindemann

Departamento de Metodologia de Ensino, Centro de Ciências da Educação, Universidade Federal de Santa Catarina, CP 5058, 88040-900 Florianópolis - SC, Brasil

Recebido em 31/8/06; aceito em 2/3/07; publicado na web em 9/11/07

\begin{abstract}
TEACHERS' VIEWS ON ENVIRONMENTAL ISSUES AND THEIR PEDAGOGICAL IMPLICATIONS FOR HIGH-SCHOOL CHEMISTRY TEACHING. This study was realized with high school Chemistry teachers from the region of and around Florianópolis (SC). It examines the pedagogical implications of these teachers' views on environmental issues, and discusses the possibilities and difficulties of bringing these issues into the Chemistry classroom. The semi-structured interviews were analyzed using Textual Discourse Analysis principles. The dominance of content-based teaching and traditional pedagogical approaches appears to hinder curricular changes. Most subjects pay little heed to environmental issues and their relation to Chemistry, and endorse a view of science as neutral, and the environment as anthropocentric - views far from Green Chemistry principles.
\end{abstract}

Keywords: environmental issues; chemistry teaching; teacher formation.

\section{INTRODUÇÃO}

A necessidade de que os processos educativos estabeleçam diálogos permanentes com situações de contexto, do ponto de vista pedagógico e dos conteúdos próprios de ensino, é uma característica importante que vem sendo evidenciada e defendida tanto por pesquisadores $^{1,2}$ quanto em documentos oficiais de orientação curricular $^{3,4}$. No entanto, as respostas a tais aspectos variam muito e parecem chegar minimamente nas salas de aula, especialmente nas disciplinas de educação científica. A origem dessas dificuldades pode estar nas fortes influências das visões epistemológicas difundidas no processo de formação inicial dos professores de Ciências e de Química ${ }^{5}$. De modo particular, os entendimentos empirista-positivistas de ciência dificultam excessivamente um ensino com abordagem contextualizada, dado que estão fortemente assentados no chamado método científico, que tem seu "homônimo pedagógico" no método centrado essencialmente no ensino de conceitos. De outra parte, as propostas de ensino de Ciências orientadas por um enfoque "contextualizado", como aquelas sustentadas pela corrente Ciência-Tecnologia-Sociedade (CTS), vêm em tese possibilitando tratar aspectos emergentes como as questões vinculadas aos problemas ambientais ${ }^{1}$.

Em grande parte associados às atividades industriais e de hiperconsumo, os chamados problemas ambientais são fortemente dinamizados pelo desenvolvimento da ciência e da tecnologia ${ }^{6}$. Conseqüentemente, evidencia-se hoje uma série de graves problemas como o aumento do aquecimento global, as contaminações de aquíferos, as queimadas e desertificações de inúmeras áreas do planeta, a crescente escassez energética, os desequilíbrios biológicos e físico-químicos; entre tantas outras manifestações que expressam uma ameaça para a sobrevivência da humanidade ${ }^{6}$. Portanto, não nos parece impróprio relacionar as atividades químicas como estando na origem de grande parte dos atuais problemas ambientais. Não obstante, muitas respostas vêm sendo constituídas e implementadas por diferentes agentes sociais, entre eles a comunidade dos Quími-

*e-mail: bebeto@ced.ufsc.br cos, que através, por exemplo, da Química Ambiental e da chamada Química Verde $(\mathrm{QV})$ vêm apresentando soluções técnicas e científicas para os problemas ambientais. Contudo, os valores apregoados pela chamada QV parecem ainda não ter chegado à educação básica, talvez como resultado do reduzido número de investigações relacionadas à temática Química e ambiente no campo da formação de professores de Química. Aspectos que confirmam o apontado por $\mathrm{Leal}^{7}$ que, ao analisar alguns currículos de cursos de Licenciatura em Química de Universidades da região sul do Brasil, concluiu que neles pouco se trata das temáticas ambientais, e quando acontece há fortes indícios de uma abordagem técnica, aspecto que segundo a pesquisadora pode estar condicionando a prática pedagógica dos docentes de Química da educação básica.

Neste panorama pareceu-nos relevante investigar, junto aos professores de Química do ensino médio possíveis implicações pedagógicas derivadas das visões que têm sobre meio ambiente, recolhendo informações da prática docente para identificar possíveis dificuldades e possibilidades para a abordagem de temas e conteúdos relacionados às questões ambientais em suas aulas.

\section{A CRISE AMBIENTAL E A FORMAÇÃO DE EDUCADORES EM QUIIMICA}

Os graves problemas ambientais da atualidade têm origem diversa, destacando-se aqueles advindos das atividades industriais, agrícolas e urbanas que, orientados historicamente por diferentes modelos de desenvolvimento socioeconômico e de progresso, vêm colocando em xeque o futuro da humanidade e do planeta ${ }^{6}$. Nesse processo tiveram e têm um papel determinante as atividades e os produtos químicos, pois uma grande parte das atividades desenvolvidas com a Química ainda desconsidera os efeitos dos sub-produtos danosos e indesejados ao meio ambiente, incluindo os seres vivos, preponderando uma racionalidade fortemente ligada à eficiência técnica e econômica que acaba secundarizando outros aspectos como o meio ambiente.

Logo, os desafios contemporâneos que se colocam à ciência indicam a incorporação de outras variáveis, como a chamada 
"sustentabilidade ambiental", de modo a orientar todas as suas práticas sociais, econômicas e políticas. E isso inclui as práticas químicas e pedagógicas, ligadas principalmente à formação teórica e prática de seus profissionais, também em processos de sua difusão em ambientes escolares.

Mesmo considerando que o conteúdo conceitual do termo "sustentável" seja ambivalente ${ }^{8}$ e com forte vínculo com sua origem econômica - dado que parece buscar essencialmente responder à necessidade de tornar sustentável o atual modelo de desenvolvimento econômico e industrial -, a sua penetração no meio acadêmico e científico vem possibilitando a incorporação de novas variáveis de reflexão e racionalidade às ciências, entre elas a preocupação com o meio ambiente. Nesse âmbito, a comunidade científica nacional e internacional tem apresentado iniciativas interessantes, dentre elas o programa norte-americano "Green Chemistry" da "Environmental Protection Agency -EPA", o Consórcio Interuniversitário INCA, na Itália, e ainda as ações da União Internacional de Química Pura e Aplicada (IUPAC), através do subcomitê para a área de "química sustentável" (Química Verde). Na perspectiva da QV, um bom exemplo é o Projeto "esverdeando o currículo de química" da Universidade de Scranton (USA) ${ }^{9}$ e, mesmo em outra perspectiva teórica, serve de exemplo o trabalho de Moradilho e Oki ${ }^{10}$ que problematiza os temas ambientais a partir dos pressupostos da educação ambiental. Já no âmbito nacional, é importante destacar o papel desempenhado pela Sociedade Brasileira de Química (SBQ) através de suas Divisões de Química Ambiental e de Ensino.

A Química Verde (QV) baseia-se no incentivo ao desenvolvimento de alternativas a serem adotadas pelas indústrias, que resultem num melhor aproveitamento dos recursos naturais, proporcionando menor poluição ambiental e menos riscos aos trabalhadores e à sociedade ${ }^{11}$. Está sustentada por doze princípios, merecendo destaque o da prevenção, que se constitui num importante valor científico que terá efeitos enormes a fim de se evitar a geração dos problemas ambientais, se assumido em plenitude pelos profissionais da Química e pelo sistema produtivo ${ }^{12}$. Portanto, sua dimensão abrange técnicas químicas e metodologias de síntese que buscam reduzir ou eliminar o uso de solventes, reagentes ou a geração de (sub)produtos nocivos ao meio biótico e abiótico. Tais aspectos são, do nosso ponto de vista, essenciais à ciência química, introduzindo por conseqüência a variável ambiental na definição de seus processos tecno-científicos e um novo fundamento para sua racionalidade acadêmica.

Entretanto, o enfrentamento amplo e profundo das questões ambientais não é uma tarefa restrita à Química ou à simples soma de várias disciplinas científicas e tampouco ao campo da ciência, mas uma questão de mudança de modelo de desenvolvimento econômico e social, e, portanto, uma questão política e de caráter planetário. Mas isso não exime que cada um desempenhe seu papel e assuma suas responsabilidades. Nesse sentido a educação química tem uma importância singular, principalmente nos processos de educação científica voltados à cidadania, com dimensão contextual e crítica. Infelizmente, tais processos têm chegado pouco às salas de aulas ${ }^{13}$.

Angotti e Auth ${ }^{14}$ ao discutirem sobre o papel da educação, particularmente da educação científica e tecnológica, frente às mudanças ambientais e comportamentais da população em conseqüência da evolução e da utilização de novas tecnologias, destacam que as compreensões de educação vinculada ao meio ambiente (sobre, no, e para o meio ambiente), quando abordadas isoladamente em uma perspectiva naturalista, são insuficientes para enfrentar a problemática ambiental. As discussões vinculadas ao desenvolvimento sustentável normalmente adotam a denominação educação para o meio ambiente por considerála portadora das melhores estratégias para a solução dos problemas, ainda que na maioria dos casos sejam soluções individualizadas. E isto estaria ligado a uma concepção que se origina com a Ciência Moderna, com seu pressuposto básico de que "tudo estava pré-determinado" e, portanto, em sua interação com a natureza o indivíduo conseguiria extrair o conhecimento nela inserido. Não obstante, é necessário considerar que aquilo que já sabemos sobre os problemas gerados ao ambiente e suas consequiências, parece suficiente para desenvolver ações no campo científico e produtivo para prevenir ou minimizar problemas ao meio. De outra parte, a adjetivação "ambiental" tem suscitado discussões por estar geralmente restrita a uma visão naturalista ${ }^{15,16}$, em que os problemas ambientais têm sido identificados com a poluição do meio, compreendido como "natural", ou seja, poluição do solo, água, ar etc. Em tal visão se desconsideram questões como a fome e a violência urbana, entre outras, como problemas ambientais. Posição da qual discordamos, uma vez que tratam de problemas de parte da biota no e do contexto social em que tais problemas "naturais" estão inseridos. De outro lado, a compreensão dos problemas da poluição e suas múltiplas relações com um "modelo" de desenvolvimento econômico e social - que negligenciou ao longo da história aspectos preventivos -, são hoje absolutamente relevantes. Nesse aspecto, uma atuação preventiva, saneadora e educativa faz-se urgente e imperativa, e em grande medida seria distinta daquelas ações meramente conservativas, orientadas pela lógica do desenvolvimento sustentável.

É nesse contexto que os processos de formação inicial de professores de Química desenvolvem suas atividades que, segundo indicativos na literatura ${ }^{7}$, ainda pouco abordam aspectos associados à prevenção como defendido pela Química Verde. Portanto, trazer alguns problemas de contexto, como a poluição do meio ambiente, estudando suas causas, conseqüências e possíveis soluções, além de um tratamento teórico, é uma possibilidade de estruturar um programa para ensinar conceitos científicos de modo a compreender melhor tais problemas. Do mesmo modo, nos cursos de graduação, esta seria uma estratégia pedagógica que balizaria as disciplinas (de Química) ambientais mais próximas de um caráter relacional, próprio da dimensão ambiental ${ }^{15}$ e de uma abordagem com dimensão contextual e problematizadora ${ }^{17}$. Tal abordagem no âmbito da educação básica pode ser promovida, por sua vez, através de uma de abordagem temática, organizada com base nos princípios da educação dialógica freireana ${ }^{18}$. A abordagem temática é uma possibilidade para organização e desenvolvimento da prática de ensino de professores de ciências, de modo a propiciar um aprendizado mais significativo para os alunos, retira-se do contexto do aprendiz temas ou questões que mais lhe tocam, para construir a partir desse processo um programa de formação. Assim, associar as perspectivas teóricas da QV e as da abordagem temática, sob orientação do enfoque CTS, nos cursos de formação inicial de professores de Química poderia constituir um caminho interessante para catalisar as almejadas transformações no ensino de Química.

\section{A PESQUISA}

A investigação foi desenvolvida com 20 professores de Química do ensino médio de 8 municípios da grande Florianópolis/SC: Águas Mornas, Antônio Carlos, Biguaçu, Florianópolis, Palhoça, Santo Amaro da Imperatriz, São José e Rancho Queimado. Na escolha dos municípios foram considerados vários aspectos, entre os quais, a possibilidade de degradação de reservas ambientais, rios e vários tipos de contaminações derivadas de atividades agrícolas exercidas na região ${ }^{19,20}$.

O número de professores constitui-se em uma amostra significativa, com $20 \%$ do total da região investigada ${ }^{21}$. Entre os critérios adotados para a composição do grupo de professores estavam a formação acadêmica e o vínculo empregatício (permanente ou tem- 
porário). Tais características foram consideradas importantes visto que estes professores, por terem vínculos mais permanentes com escola (expresso via lotação) e com as questões da comunidade escolar e da região, bem como a sua opção profissional pela química e pela licenciatura, poderiam exprimir de forma melhor as dificuldades e possibilidades de trabalharem com questões ambientais nas aulas de química. Tais informações foram obtidas junto à Secretaria Estadual da Educação de Santa Catarina. Assim, o grupo pesquisado foi constituído de $90 \%$ de professores graduados em Química - destes 85\% com licenciatura -, e 65\% com mais de 6 anos de docência na área. Os outros $10 \%$ da amostra eram formados por graduandos em Química ou Ciências Naturais. Todos os professores lecionavam na rede pública estadual - dois deles também na rede privada -, sendo que $75 \%$ estavam lotados há mais de 2 anos na mesma instituição escolar. Em relação ao vínculo empregatício, $80 \%$ são efetivos nas escolas em que estão lotados e os demais são temporários. O regime de trabalho semanal em sala de aula dos professores caracterizou-se da seguinte forma: $30 \%$ com 10 a $20 \mathrm{~h} ; 55 \%$ com 21 a $40 \mathrm{~h}$ e $15 \%$ com mais de $40 \mathrm{~h}$. Metade dos entrevistados informou que possuem algum curso de aperfeiçoamento. Ressalta-se que a maioria dos docentes afirmou não dispor ou não utilizar tempo para o planejamento das aulas.

Para obter as informações qualitativas realizaram-se entrevistas semi-estruturadas ${ }^{22}$ com os objetivos de: identificar aspectos da prática pedagógica; analisar os possíveis modos de abordagem de temas em sala de aula; compreender as relações entre os seres humanos, a Química, o meio ambiente e as questões ambientais; e entender as dificuldades e/ou possibilidades para abordar questões ambientais nas aulas de Química. A análise qualitativa das informações foi orientada pelos princípios da análise textual discursiva ${ }^{23}$ que é constituída pelas etapas de unitarização, categorização e comunicação. Na etapa de unitarização deu-se a fragmentação dos textos originados das entrevistas transcritas em unidades de significado e que na etapa de categorização foram agrupados de acordo com suas semelhanças semânticas. Por fim, na comunicação elaborou-se um texto descritivo e interpretativo (metatexto), com as categorias de análise. $\mathrm{Na}$ análise textual discursiva considera-se que é a interpretação que possibilita transcender o imediato, favorecendo assim a construção de significados sobre o fenômeno estudado. Logo, somente a descrição seria insuficiente para compreender o discurso a respeito do assunto investigado. As citações no "metatexto" contribuem para que se tenha uma visão acerca do discurso sobre qual se descreveu. Além disso, foi dado um tratamento quantitativo (Tabela 1) às compreensões docentes predominantes das categorias de análise, quais sejam: visão de meio ambiente, a problemática ambiental e sua relação com a química e prática pedagógica. Os nomes dos professores entrevistados foram substituídos por uma letra [X].

\section{Visão de meio ambiente}

Entre as visões sobre meio ambiente explicitadas pelos entrevistados (Tabela 1), evidenciou-se a racional: “[...] se nós não cuidarmos bem da água, solo; da natureza como um todo, do ar, nossa existência está com os dias provavelmente contados! [...] tem a ver com a própria sobrevivência da espécie humana" [N]. O termo natureza às vezes surge com o significado de recurso inesgotável e outras vezes com o significado de sustentável ${ }^{24}$, indicando implicitamente, por consequiência, que esta também pode ser destruída, tal como aponta o relato. A fala parece ainda justificar a preocupação com o meio ambiente devido unicamente à sua relevância para a existência da espécie humana, interpretação que pode estar baseada num entendimento racionalista da relação "homem-natureza". E isso se manifesta, parti- cularmente, quando o mesmo menciona a necessidade de "cuidar" dos bens naturais, referindo-se apenas à relevância de nos adaptarmos às condições limitantes do ambiente, dado que tais bens naturais podem se esgotar. Tal perspectiva quando expressa em conteúdos de ensino pode ter como meta apenas disciplinar mecanicamente os sujeitos.

Essa compreensão foi demarcada por Tozoni-Reis ${ }^{25}$ ao analisar os referenciais teóricos de "educadores ambientais" de cursos de graduação em Química, Biologia e Geografia, ressaltando a predominância da tendência racional entre os docentes de Química. Segundo a autora, "a relação homem natureza não é definida naturalmente pela natureza, nem é definida cientificamente pela razão, mas construída social e politicamente pelo conjunto dos homens" (p. 89). E assim, nesta condição, a idéia de neutralidade científica é recusada com veemência, e, portanto, o princípio educativo não é a ideologia da harmonia nem o fetiche do conhecimento científico, mas as efetivas necessidades histórico-concretas da sociedade. De certo modo, tais aspectos também são ressaltados por Altvater ${ }^{26}$ ao destacar os princípios contraditórios da eficiência econômica e da eficácia ecológica e ao discutir o preço que pagamos pela idéia linear de progresso que atualmente predomina e porque o desenvolvimento é contrário ao meio ambiente.

Assim, a compreensão sobre a relação entre natureza e humanidade precisa superar a visão dicotômica do "mundo natural" como oposto ao "mundo humano" e da perspectiva conservacionista que acredita na interferência humana sempre como uma ameaça ao "meio natural" 27 . A presença da visão naturalista entre professores pode ter como conseqüência a idéia de que a educação se reduz à função de adaptar os indivíduos a um mundo pré-determinado pelos processos naturais ${ }^{25}$. Essa compreensão naturalista foi bem ilustrada pela fala de um professor: "todo problema ambiental tem relação com a poluição. Indústrias que lançam resíduos nos esgotos, poluição do ar, poluição de rio, poluição do solo, em função do avanço que é tão grande da tecnologia" [G].

Outra idéia que emergiu em um dos relatos foi o antropocentrismo: “o homem é que proporciona este desequilíbrio (ambiental)..." [Q]. A gênese do pensamento antropocêntrico teve a influência da teologia cristã, para a qual "a natureza existe a serviço do homem e ele é o centro de todas as coisas" (p. 74) ${ }^{24}$. Uma das implicações dessa compreensão, por exemplo, é o comportamento exploratório e impiedoso dos humanos sobre o meio biótico e abiótico, com entendimentos de meio ambiente que reforçam a dicotomia humanidade-natureza, de tal modo que a "natureza" parece existir unicamente para nos servir. $\mathrm{E}$, é diante de tais aspectos que nos parece interessante ressaltar a reflexão feita por Chomsky, citado por Medeiros ${ }^{24}$, sobre a inexistência de um único conceito de natureza, antropocêntrico ou biocêntrico. Pare ele, nomeamos a natureza de social, biológica, histórica e cultural, e, apesar disso, ela ainda conserva sua própria dinâmica e o homem não tem tanto o controle sobre ela como tem de sua própria sociedade. Tal perspectiva parece reforçar a idéia de multidimencionalidade do termo natureza, aspecto trabalhado tanto por Maturana e colaboradores $^{28}$ como por Moraes $^{16}$.

Contudo, ainda que manifestada por apenas 2 professores, também emergiu uma compreensão que parece superar uma visão antropocêntrica, que realça a presença da espécie humana como parte do meio ambiente:

[...] a relação com a vida se dá na medida em que o ser humano, que está nesse ambiente, começa também a ser afetado pelos problemas ambientais [N].

O entrevistado parece reconhecer o ser humano como constituinte do meio ambiente, portanto interagindo com o meio biótico e 
abiótico, ainda que não enfatize a importância da biodiversidade. Nesse aspecto, Vilches e Gil ${ }^{6}$ discutem que "a natureza é diversa por definição e necessidade. E, por isso, a biodiversidade é a maior expressão de sua lógica. E, portanto a garantia de seu êxito" (p. 69). Mas, caminhar em direção a um distanciamento da visão naturalista e antropocêntrica de meio ambiente não se reduz ao reconhecimento da diversidade biofísica. É preciso incorporar a isso o conceito de sociobiodiversidade, que não considera a presença humana como incondicionalmente destrutiva do meio "natural", pois o ser humano interage com este meio "natural" e pode muitas vezes provocar um aumento da biodiversidade devido à ação exercida justamente em tal ambiente ${ }^{27}$. Nesse caso, é uma interação que enriquece o meio ambiente e que, a princípio, é desprezada pela visão conservacionista, o que a reforça como sendo reducionista e pouco eficiente no vislumbramento de soluções à problemática ambiental ${ }^{27}$.

Portanto, a compreensão predominante de meio ambiente dos professores caracterizou-se basicamente como naturalista e racional, sendo o meio ambiente reduzido à dimensão "natural", e a relação humanidade-natureza definida pela razão, predominando a dicotomia entre ser humano e meio ambiente. Poucas compreensões se distanciaram destas visões. Todavia, entendemos que um dos limites para discutir a relação entre a Química e os problemas ambientais, em processos educativos, pode ser justamente a presença de visões reducionistas de meio ambiente, como as expressas pela maioria dos investigados.

\section{A problemática ambiental e sua relação com a Química}

Nossos investigados caracterizaram os problemas ambientais, em geral, de forma reducionista e fortemente fragmentada, apontando muitas vezes as atividades químicas como responsáveis pelos problemas ambientais: "os problemas ambientais estão sempre relacionados com a química" $[\mathbf{J}]$. Esta compreensão parece reforçar uma conotação pessimista à Química, negando suas evidentes contribuições sociais e científicas, inclusive para as questões ambientais. Expressa também uma compreensão simplista sobre o que vem a ser um problema ambiental. Contudo, outros professores pesquisados apontaram igualmente para as contribuições da Química:

[...] afinal a química é boa ou má? Então existe uma relação com estes distúrbios e as atividades químicas! Então a gente mostra se utilizar a química de uma maneira correta, a gente pode utilizar isso tranqüilamente, sem causar distúrbio nenhum $[\boldsymbol{H}]$.

Mas neste relato aparece, mesmo que sutilmente, um entendimento linear de Ciência buscando caracterizar a Química como simplesmente 'boa ou ruim', sem problematizar o contexto da produção científica e os outros aspectos que a permeiam como, por ex., os aspectos econômicos, políticos, sociais e culturais, e que têm relação com os problemas ambientais. É nesse sentido que parece pouco eficiente sugerir somente medidas técnicas para solucionar problemas ambientais, visto que não são acompanhadas de medidas sociais e culturais ${ }^{29}$.

Há também avanços na compreensão dos problemas ambientais ao não centralizá-los somente nas atividades químicas: "o homem é que proporciona esse desequilíbrio. Não só com as atividades químicas, mas com as atividades biológicas e físicas" [Q]. Embora este professor não mencione os aspectos econômicos e sociopolíticos, igualmente influentes nos problemas ambientais, parece entender que há uma complexa relação entre as atividades humanas com tais problemas. Mesmo assim, nessa visão, a origem dos desequilíbrios está associada somente à atividade humana, desco- nhecendo o que já é consolidado pela ciência sobre os períodos de grande transformação no planeta, ocorridos em épocas anteriores à humanidade.

Ainda nesta perspectiva surgiu a idéia dos químicos assumirem as responsabilidades para resolverem os problemas ambientais: "o químico, [...] ele tem que além de conscientizar as pessoas, ele mesmo tem que correr atrás pra tentar resolver estes problemas aí de poluição" [S]. Este é um aspecto importante, visto que existe a necessidade da Química se preocupar com os problemas ambientais, superando assim uma visão neutra de ciência. De fato, as atividades químicas podem ser (co)responsáveis por problemas ambientais, mas a efetiva solução dos problemas não depende apenas dessa ciência, pois como realçamos anteriormente, existem outros fatores que influenciam nesta problemática. Ou seja, defendemos a superação da perspectiva salvacionista da Ciência e Tecnologia (CT), segundo a qual CT sempre está associada com a solução dos problemas da humanidade ${ }^{29}$. Do mesmo modo, atribuir individualmente às pessoas ou aos profissionais a exclusiva responsabilidade pelas causas e soluções dos problemas ambientais acaba por secundarizar a imensa responsabilidade do sistema produtivo-industrial, político e econômico.

A fragmentação do entendimento das causas e das possíveis soluções aos problemas ambientais pode refletir uma compreensão superficial e reducionista de meio ambiente, que dificulta ainda mais a incorporação dessa temática pela química, seja do ponto de vista epistêmico ou pedagógico.

Da análise das entrevistas foi possível depreender, em quantidade modesta (5 entrevistados), manifestações associadas ao discurso contemporâneo acerca de produtos e processos e suas implicações ambientais, em consonância com alguns princípios da Química Verde, a exemplo da prevenção. Um dos professores afirma: “[...] o químico [...] é o responsável direto por produzir o material que está sendo lançado e o professor de Química [...] tem que fazer os alunos já começarem a ter entendimento [...] que nos produtos que poluem tem forma de evitar isso aî" [F]. Na fala do professor emerge a importância de se incluir no ensino de Química a abordagem de questões ambientais, vinculando-as a processos e atividades químicas industriais, bem como, implicitamente, a questão da não neutralidade do conhecimento científico. Ainda que o mesmo centre no químico e no professor de química tanto a responsabilidade pelos problemas ambientais quanto a sua solução.

Também emergiram entre os entrevistados (3 professores) aspectos ligados ao saneamento ambiental (remediação da poluição ambiental e tratamento de resíduos):

\footnotetext{
Tratamento de resíduos nas indústrias é utilizar na incineração do lixo para amenizar a saída de gases tóxicos. [...] tem a parte que deve partir da gente, da população: [...] evitar o descarte de pilhas e baterias, pois possuem metais pesados, por exemplo [Q].
}

O saneamento é um aspecto relevante e necessário, porém pode ainda ser considerado como uma ação mais restrita a remediar ou reparar um problema, que nem sempre é resolvido de maneira satisfatória e que muitas vezes persiste. O que precisa ser perseguido é uma atuação preventiva que atue na origem, em processos de emissão e descarte, aumentando assim a eficiência e a segurança nos sistemas, como defende a QV, sem com isso reduzir a solução dos problemas a uma dimensão puramente técnica ${ }^{30}$. Na passagem destacada (professor [Q]), é ressaltada a necessidade da participação social para contornar o problema, aspecto que precisa ser melhor trabalhado pelo ensino de química. O discurso da preservação ambiental implícito na fala do entrevistado [Q] é uma manifestação bastante presente no imaginário de professores de Quími- 
ca do ensino médio ${ }^{31}$. Contudo, em nossa pesquisa, tal questão aparece fortemente associada a uma questão individual e a um comportamento ético e atitudinal das pessoas.

Nessa direção, outro investigado ressalta o papel docente na inserção dos alunos na discussão das questões ambientais:

O químico tem ligação direta com a produção, com o que a indústria faz. [...] ele tem condições de fornecer subsídios, orientações e sugestões. [...] ele tem a possibilidade de sugerir novas formas menos poluentes e tudo mais. Enquanto que o professor é o formador de consciência, [...] teria a função de trabalhar na conscientização dos alunos numa perspectiva (de) serem inseridos num mercado de trabalho e até em nivel de produção e de repente como empresário, ter uma consciência maior como trabalhar a questão da natureza. [N]

Essa compreensão parece avançar em direção a um entendimento mais complexo, não atribuindo à ciência a incumbência exclusiva da solução dos problemas ambientais. Percebe outros elementos influentes e importantes na tomada de decisões para evitar ou minimizar a poluição. Ou seja, ao mesmo tempo em que supera a visão de neutralidade científica, aponta para as implicações da dimensão econômica para a Ciência. Em relação à possibilidade de conscientização das pessoas, isto parece atribuir uma responsabilidade ao professor que precisa ser repensada, pois, parafraseando Freire ${ }^{17}$, ninguém conscientiza ninguém, ninguém se conscientiza sozinho, os homens se conscientizam em comunhão com o mundo. De outra parte, entendemos que o professor ao salientar a necessidade de conscientização dos alunos está chamando a atenção para a importância do ensino de atitudes e valores, e, portanto, de uma ética ambiental, entendimento que compartilhamos. Tais aspectos precisam ser acompanhados dos conteúdos disciplinares dentro de uma abordagem temática ${ }^{18}$ que sustente posições e comportamentos públicos, como aqueles relacionados ao enfrentamento dos problemas ambientais pela escola ${ }^{14}$.

Questionados se conheciam ou tinham ouvido sobre Química Verde, $65 \%$ dos entrevistados afirmaram positivamente e indicaram que a principal fonte de informação sobre isso foi obtida através de revistas, livros, jornais, noticiários e dos cursos de graduação e formação continuada. Porém, o conjunto dos professores ao ser questionado sobre se conhecia termos relacionados, mas não exclusivos da QV, tais como (a) economia atômica, (b) eco-eficiência, (c) quantificação de consumo energético, (d) novas metodologias de sínteses, (e) fontes renováveis, (f) subprodutos menos tóxicos em estratégias sintéticas, apresentaram indícios de pouca familiarização com tais termos, como mostra a Figura 1.

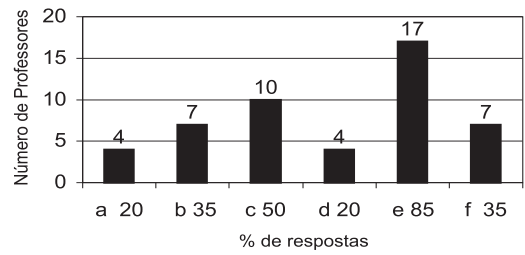

Temas:

(a) economia atômica: 20

(b) eco-eficiência: 35

c) quantificação de consumo energético: $\mathbf{5 0}$

d) novas metodologias de sínteses: 20

(e) fontes renováveis: $\mathbf{8 5}$

(f) sub-produtos menos tóxicos, em estratégias sintéticas: 35

Figura 1. Termos relacionados à Química Verde que os professores dizem conhecer

O termo mais conhecido foi fontes renováveis, fato que é compreensível se o principal meio de conhecimento dos professores são os meios convencionais de informação, onde esta questão é mais freqüentemente abordada. Já os outros termos são mais específicos da Química e têm veiculação mais restrita ao meio científico. A pouca citação dos demais termos pode ser indício do acesso precário dos docentes aos meios de divulgação de pesquisas científicas, participação em eventos científicos na área de Química e ensino de química. Entretanto, se consideramos que metade dos professores entrevistados freqüentou algum tipo de curso de especialização relativamente recente na área de atuação, suas respostas parecem pouco condizentes ou podem ser um indicativo de que estes cursos estão à margem das discussões sobre questões contemporâneas da Química, como a QV. Aliás, a própria literatura científica aponta que a QV tem sido pouco discutida no país ${ }^{12}$.

Os princípios da QV, somados às discussões do enfoque CTS e às contribuições freireanas para o ensino de Ciências, entre outras, podem trazer à formação dos educadores, para serem tratados em sala de aula, elementos tecno-científicos, éticos, culturais e pedagógicos significativos sobre a relação entre os problemas ambientais e as atividades químicas. Isso pode ser um modo de favorecer discussões em torno de aspectos ligados à geração dos problemas ambientais e possíveis contribuições para solucionar tais problemas. A compreensão pedagógica de que a ciência busca dar respostas a muitas das necessidades humanas e que por isso deve ter responsabilidades éticas com suas ações deveria perpassar todos os momentos formativos desde a educação geral e científica até a profissionalizante.

\section{Prática pedagógica: da supremacia do conteudismo ao ensino significativo}

A análise do diálogo estabelecido com os professores fez também emergir fragmentos significativos que categorizamos como "ensino do cotidiano", "temas associados aos conteúdos programáticos" e "aproximação de uma abordagem temática", e que foram discutidos em conjunto, dado que expressam tendências fortes de organização e desenvolvimento dos programas de ensino aplicados e defendidos pelos professores. A distinção entre abordagem temática e conceitual é uma importante questão para compreender melhor a formação dos professores entrevistados, particularmente para o enfrentamento de temáticas ambientais no ensino de Química. Segundo Delizoicov, Angotti e Pernambuco ${ }^{18}$ a abordagem temática é uma forma de organização curricular com base em temas a partir dos quais são selecionados os conteúdos da disciplina, o que implica que os conceitos científicos são subordinados aos temas, sendo ensinados para compreendê-los do ponto de vista científico. Já na abordagem conceitual a organização curricular é estruturada pelos conceitos científicos, como conteúdos de ensino. O chamado ensino do cotidiano ${ }^{32}$, que se restringe a exemplificações e ilustrações dos conteúdos conceituais, está muito mais próximo da perspectiva curricular que seleciona e estrutura o conhecimento a partir dos conceitos. A subordinação dos temas aos conteúdos programáticos clássicos traz limitações à compreensão dos mesmos pelo aluno, além de estabelecer restrições pedagógicas importantes, como o baixo envolvimento do aluno através de seus saberes, considerando que o domínio conceitual não é por ele previamente conhecido e sim pelo professor.

Os entrevistados apontaram diferentes possibilidades de articulação dos conteúdos disciplinares com a abordagem das questões ambientais. $\mathrm{O}$ amplo espectro de compreensões vai desde abordagens que ainda primam pelo conteudismo, até aquelas nas quais o foco se desloca para a compreensão de problemas relevantes do ponto de vista das implicações sociais. Mas, o que predominou entre os investigados foi a manifestação de uma prática pedagógica tradicional (Tabela 1) mascarada com o "ensino do cotidiano": Parece impor "[...] porque eu trago é o exemplo do dia-a-dia, mas 
não que eu aborde um tema desses, [...] tanto que eu já tive dificuldade em responder como que quimicamente vou evitar a poluição" [E]. Trata-se, portanto da abordagem conceitual, com o foco central na apreensão do conhecimento científico por parte dos alunos e o professor apenas ilustrando os conteúdos com fatos do cotidiano, também com o escopo de motivar o aluno ${ }^{32}$. Nesse sentido, um dos princípios fundamentais, estruturadores do currículo, estabelecido pela reforma curricular, a contextualização, parece ser confundido com as exemplificações do cotidiano dos alunos. As aulas diferenciadas são compreendidas pelos docentes como o ensino de conceitos "recheados" com exemplos do dia a dia. Isto parece evidenciar que os elementos teóricos que sustentam os novos documentos de orientação curricular têm uma compreensão diferenciada pelos professores daquelas que os autores propuseram.

Outros investigados forneceram indícios de uma aproximação com práticas pedagógicas alternativas, conforme evidenciado na Tabela 1, expressando uma compreensão mais ampla dos problemas ambientais que poderia levar a uma aproximação entre as perspectivas defendida pela QV, presentes no enfoque CTS e na educação freireana.

Assim, existiram situações em que ocorrem aproximações a alguns pressupostos da abordagem temática, com depoimentos que manifestaram preocupações pelos aspectos políticos, sociais e ambientais trazidos pelo tema proposto, como por ex.:

[...] ontem no Fantástico ouvi um assunto: queima de petróleo. Já levei prá sala de aula tanto a questão ambiental quanto a questão política; às vezes levando prá interdisciplinaridade. As questões políticas e geográficas $[\boldsymbol{L}]$.

Defensores do enfoque CTS no ensino enfatizam a possibilidade pedagógica da promoção de debates utilizando-se de notícias veiculadas pela mídia, cuja finalidade principal em sala de aula é contemplar uma formação cidadã ${ }^{33}$. Numa perspectiva freireana ${ }^{34}$, a educação não precisa, se opor à televisão ou à mídia, mas estimular uma maneira crítica de pensar sobre o que é comunicado, pois sabemos que este processo de comunicação não é neutro, pelo contrário, tem um caráter fortemente ideológico.

Para parte dos investigados a abordagem de temas ambientais no ensino de Química se justifica pela importância que eles podem representar para os discentes, como relata um professor:

[...] você primeiro tem que fazer os alunos sentirem a necessidade [...] desse tema. Não adianta, em sala de aula, ou no quer que seja, ficar "vomitando" uma porção de coisas e aquilo não dizer nada. Então, os alunos têm que sentir a necessidade desse tema [N].

Do relato, pode-se depreender que nem todo tema pode ser de interesse dos alunos, o que é pedagogicamente relevante. Contudo, podem existir temas importantes para serem tratados pelo ensino de ciências, devido a sua relevância social, política e ambiental, mas que ainda os estudantes não os solicitam de maneira espontânea. Assim, organizar o ensino a partir de temas poderia contribuir para o desenvolvimento de um processo dialógico em sala de aula, já que os temas, ao contrário de uma perspectiva conteudista, ou são supostamente de domínio dos alunos ou podem vir a ser, se significativo for em seu contexto. Ainda nessa direção, a fala do professor parece justamente contemplar a idéia de que o ensino pode ser bem sucedido quando o aluno se dispõe a aprender, pois a aprendizagem é derivada da ação de um sujeito, caracterizada pela intenção entre ele e o meio que está inserido, incluindo a dimensão natural e social ${ }^{18}$.

É nessa direção que outros professores parecem avançar ao sinalizarem critérios para a escolha dos assuntos a serem abordados:
Eu acho que só trazendo o que eles têm na comunidade deles para tornar mais importante e mais significativo. E, não adianta eu querer falar lá da região carbonífera para eles que não sabem nem como é que é uma mina, nem nunca tiveram contato [...] tem que ser coisas mais voltadas para a comunidade deles [S].

Compartilhamos com o investigado que o contexto dos alunos pode ser um ponto de partida para a eleição dos assuntos. Tratar dos problemas locais, como sugere o relato acima, pode cumprir a função de mostrar aos estudantes a relevância do que é ensinado. A partir de uma perspectiva freireana ${ }^{17}$ os temas são os estruturadores da programação escolar e não mais os conteúdos disciplinares. Assim, os conteúdos científicos são subsumidos na estruturação do programa, aparecendo na medida que o tema for exigindo. Entendemos que tal enfoque responde aos questionamentos mais tradicionais como "para quem ensinar e para quem interessa o conteúdo selecionado?".

Portanto, a maioria dos investigados revelou uma crença na organização curricular a partir dos conteúdos conceituais para ensinar a respeito dos problemas ambientais, o que às vezes pode ser acompanhado de um ensino do cotidiano. Já a aproximação de um ensino baseado em uma abordagem temática e de um ensino com enfoque CTS sobre a problemática ambiental foi pouco expressivo entre os professores. Isso não nos surpreendeu, pois a literatura tem destacado a predominância de um ensino de química conteudista. Defendemos que os processos de formação docente problematizem as formas de seleção dos conteúdos constituintes do programa escolar, de modo a explicitar as limitações da perspectiva conteudista, de modo especial, para, a abordagem de problemas ambientais no ensino.

Na Tabela 1 pode-se melhor comparar as categorias que foram organizadas para expressar as diferentes visões dos entrevistados sobre meio ambiente, prática pedagógica e a problemática ambiental e sua relação com a química. Cada uma destas categorias foi ainda organizada para relatar as diferentes compreensões acerca dos seus aspectos constitutivos, que foram sendo interpretadas e discutidas a partir de diferentes referenciais teóricos, ao longo desse texto.

Assim, da análise das manifestações dos entrevistados sobre as visões de meio ambiente, da problemática ambiental e sua relação com a química, e do relato da prática pedagógica dos mesmos, busca-se a seguir discutir as dificuldades e possibilidades para a abordagem de temas e conteúdos relacionados às questões ambientais nas aulas de química.

\section{Condições pedagógicas para haver mudança}

Os professores apresentaram a falta de condições pedagógicas como justificativa para limitações em sua prática docente. Elegeram estas condições como fatores, na maioria das vezes determinantes, para não adotar qualquer mudança nos assuntos e na forma de ensinar química. Entre os aspectos que dificultam ou até impedem o desenvolvimento de questões relacionadas à problemática ambiental nas aulas de Química, segundo os professores, estão: a falta de tempo do professor; a carga horária semanal insuficiente da disciplina; a falta de laboratório; a falta de recursos audiovisuais, de informática e humanos e de material didático; as condições de trabalho docente (jornada de trabalho, número de turmas e número excessivo de alunos por classe); salário e os alunos "desinteressados". Alguns desses aspectos podem ser evidenciados na fala de um dos professores, que apontou para a importância do laboratório, de materiais didáticos, da internet, do tempo e dos salários dos docentes: 
Tabela 1. Tratamento quantitativo das compreensões docentes predominantes das categorias de análise

\begin{tabular}{|c|c|c|c|c|c|c|c|c|c|c|c|c|c|c|c|c|c|c|c|c|c|}
\hline \multirow[t]{2}{*}{ Categoria } & \multirow[t]{2}{*}{ Compreensão } & \multicolumn{20}{|c|}{ Professor } \\
\hline & & A & $\mathrm{B}$ & $\mathrm{C}$ & $\mathrm{D}$ & $\mathrm{E}$ & $\mathrm{F}$ & G & $\mathrm{H}$ & I & $\mathrm{J}$ & $\mathrm{K}$ & $\mathrm{L}$ & M & $\mathrm{N}$ & $\mathrm{O}$ & $\mathrm{P}$ & Q & $\mathrm{R}$ & $\mathrm{S}$ & $\mathrm{T}$ \\
\hline \multirow[t]{7}{*}{ Visão de Meio Ambiente } & Racional & & & & & & & & $\mathbf{X}$ & & $\mathbf{X}$ & & & & $\mathbf{X}$ & & & & & & \\
\hline & Naturalista & & $\mathbf{X}$ & $\mathbf{X}$ & $\mathbf{X}$ & & $\mathbf{X}$ & $\mathbf{X}$ & & $\mathbf{X}$ & & $\mathbf{X}$ & & $\mathbf{X}$ & & $\mathbf{X}$ & & & & $\mathbf{X}$ & $\mathbf{X}$ \\
\hline & Antropocêntrica & & & & & & & & & & & & & & & & & $\mathbf{X}$ & & & \\
\hline & Globalizante & & & & & & & & & & & & $\mathbf{X}$ & & & & & & & & \\
\hline & Superação da & & & & & & & & & & & & & & $\mathbf{X}$ & & & & & & \\
\hline & visão antropocêntrica & & & & & & & & & & & & & & & & & & & & \\
\hline & Não identificada & $\mathbf{X}$ & & & & $\mathbf{X}$ & & & & & & & & & & & $\mathbf{X}$ & & $\mathbf{X}$ & & \\
\hline \multirow{9}{*}{$\begin{array}{l}\text { Problemática ambiental } \\
\text { e sua relação com a química }\end{array}$} & Saneamento & & $\mathbf{X}$ & $\mathbf{X}$ & & & & & & & & & & & & & & & & $\mathbf{X}$ & \\
\hline & Prevenção & & & & & & & $\mathbf{X}$ & & & & & & & $\mathbf{X}$ & $\mathbf{X}$ & & & $\mathbf{X}$ & $\mathbf{X}$ & \\
\hline & $\begin{array}{l}\text { Conscientização para } \\
\text { ação individual }\end{array}$ & & $\mathbf{X}$ & $\mathbf{X}$ & & & $\mathbf{X}$ & $\mathbf{X}$ & $\mathbf{X}$ & & & $\mathbf{X}$ & $\mathbf{X}$ & $\mathbf{X}$ & $\mathbf{X}$ & $\mathbf{X}$ & & $\mathbf{X}$ & $\mathbf{X}$ & & $\mathbf{X}$ \\
\hline & $\begin{array}{l}\text { Conscientização para } \\
\text { ação coletiva }\end{array}$ & & & & & & & & & & $\mathbf{X}$ & & & & & & $\mathbf{X}$ & & & $\mathbf{X}$ & \\
\hline & Reducionista/simplista & & $\mathbf{X}$ & & $\mathbf{X}$ & $\mathbf{X}$ & $\mathbf{X}$ & & & & $\mathbf{X}$ & & & & $\mathbf{X}$ & & & & $\mathbf{X}$ & & $\mathbf{X}$ \\
\hline & Superação de visão & & & & & & & & & & & $\mathbf{X}$ & $\mathbf{X}$ & $\mathbf{X}$ & & & $\mathbf{X}$ & $\mathbf{X}$ & & $\mathbf{X}$ & \\
\hline & Reducionista & & & & & & & & & & & & & & & & & & & & \\
\hline & Visão linear de ciência & & & & & & & & $\mathbf{X}$ & & & & & & & $\mathbf{X}$ & & & & & \\
\hline & Não identificada & $\mathbf{X}$ & & & & & & & & $\mathbf{X}$ & & & & & & & & & & & \\
\hline Prática & Tradicional & $\mathbf{X}$ & $\mathbf{X}$ & $\mathbf{X}$ & $\mathbf{X}$ & $\mathbf{X}$ & $\mathbf{X}$ & & & & $\mathbf{X}$ & $\mathbf{X}$ & $\mathbf{X}$ & $\mathbf{X}$ & & $\mathbf{X}$ & & & $\mathbf{X}$ & & $\mathbf{X}$ \\
\hline Pedagógica & Alternativa & & & & & & & $\mathbf{X}$ & $\mathbf{X}$ & $\mathbf{X}$ & & & $\mathbf{X}$ & & $\mathbf{X}$ & & $\mathbf{X}$ & $\mathbf{X}$ & & $\mathbf{X}$ & \\
\hline
\end{tabular}

[...] falta de um laboratório, falta de material didático, falta de internet para poder pesquisar na escola e falta de tempo do professor e os baixos salários que também não animam a gente fazer muita coisa. [...] Pode-se fazer muito mais, é se dedicar mais se a gente ganhasse um pouco mais... [...] eu precisaria de um tempo na escola mesmo, mas eles querem que a gente fique em sala de aula, que a gente dê dezesseis aulas e nem tempo para ti pesquisar e para ti fazer outras coisas, criar alternativas. Eles não dão tempo $[\boldsymbol{P}]$.

Parece haver algum consenso entre os pesquisadores em ensino de Química que a presença do laboratório didático, como um espaço físico estereotipado com vidrarias e reagentes convencionais, não é condição essencial para o desenvolvimento de atividades experimentais, ainda que o laboratório seja um espaço importante na escola ${ }^{35,36}$. Atualmente existe um incentivo à utilização de materiais e reagentes de baixo custo e facilmente acessíveis para promover experimentos em sala de aula. Contudo, não são as condições materiais em si que favorecem a aprendizagem dos estudantes, mas sim o modo como o docente realiza a atividade.

Também aparece com ênfase, na fala do entrevistado, a necessidade de tempo para a pesquisa, provavelmente para a obtenção de informações sobre os temas de ensino, e isso se dá pelo destaque à necessidade de acesso a materiais didáticos e à internet para a abordagem de questões ambientais no ensino de Química. A sua fala aponta para um aspecto que precisa ser considerado pelas políticas públicas educacionais, ou seja, a garantia do acesso aos materiais alternativos ao livro didático, que embora possa ter suas insuficiências superadas, não precisa ser o único recurso para o planejamento das aulas ${ }^{18}$.

O relato do investigado ainda ressalta a necessidade de melhoria dos salários e condições de trabalho. Entendemos que por si só a melhora dos salários dos educadores não resolverá os problemas da educação, Contudo, essa reivindicação é um direito e um dever dos docentes ${ }^{37}$. Apostamos, como realça o investigado, na necessi- dade de melhorar as condições de trabalho docente, pois este é um aspecto fundamental para o planejamento das atividades de ensino coerentes com as discussões atuais sobre o ensino de Ciência. Sabese que enquanto as políticas educacionais desconsiderarem tais fatos, dificilmente os professores conseguirão transformar sua prática pedagógica, apesar dos seus esforços ${ }^{38}$.

Muitos entrevistados também apontaram a necessidade de recursos humanos para a melhoria das condições de trabalho: “...o que falta mesmo é um técnico de laboratório... um professor de 40 h, 20 h/aula...a questão financeira...(os) alunos também (são) desinteressados" [M]. Novamente emerge a importância das atividades experimentais, porém dando enfoque ao apoio de recursos humanos em detrimento de recursos materiais e do seu próprio tempo para planejar e desenvolver tais atividades.

Entre outras coisas, o professor ainda se apóia no desinteresse dos alunos para justificar a dificuldade para a abordagem de questões ambientais. Nessa perspectiva é remetido ao Outro a responsabilidade pela ausência dessas questões no ensino de Química. É uma visão heterônoma que precisa ser problematizada na prática docente, visto que empobrece o discurso pedagógico profissional. Há tempos os discentes são responsabilizados pelos problemas presentes na sala de aula, particularmente aqueles que se referem à aprendizagem. Nessa ótica, Coelho ${ }^{39}$ denominou de "barreira ideológica" essa forte tendência em transferir ao outro - sobretudo estudantes - a dificuldade de se organizar um ensino através da abordagem temática.

O número de aulas de Química também foi apontado por vários professores investigados como uma limitação: "a parte de alimentos, a parte de drogas, [...] é o problema e a realidade deles, também desta escola aqui... Eu já trabalhei... mas com 2 aulas não tem como" $[\mathbf{E}]$. A fala contempla tacitamente uma crítica à redução de 3 para 2 h/aula semanais na disciplina de Química nas escolas estaduais de Santa Catarina. Entendemos que essa redução na carga horária traz implicações limitantes para a abordagem das questões ambientais, embora não a torne inviável ${ }^{39}$. Fator este que também seria limitante para uma abordagem conteudista, como acreditam muitos professores de Química. 
Os entendimentos sobre como ensinar e aprender também apareceram no discurso dos docentes a respeito da abordagem de questões ambientais. Há claros indicativos da compreensão de que o aluno é um receptáculo de informações e o professor, um detentor do saber: "o aluno está ali para aprender e nós temos que passar o conteúdo da forma mais acessível possível" [F]. As fortes marcas do modelo transmissão/recepção, que possivelmente caracterizaram muitas das disciplinas no curso de graduação, refletem-se explicita ou implicitamente no discurso dos docentes. Compreendemos que é contraditório apostar em uma abordagem temática em sala de aula com uma perspectiva de ensino tradicional. Em outras palavras, se almejamos tratar de problemas ambientais relevantes e do contexto dos estudantes, está implícita neste processo a participação discente em todos os momentos e atividades pedagógicas. Tal posicionamento é compartilhado por Santos ${ }^{2}$ na defesa de estratégias dialógicas de ensino, em uma educação voltada para a cidadania.

Também é notória a indistinção entre currículo imposto e currículo proposto: "se a gente seguir todo o currículo do ensino médio, com relação à Secretaria de Educação, a gente não consegue abordar todos os assuntos" [Q]. Emerge a idéia que o currículo se reduz a uma listagem de conteúdos, geralmente conceituais, a ser obrigatoriamente cumprida. Parece que estes professores têm buscado um diálogo análogo também com o livro didático e com as orientações curriculares oficiais, compreendendo-os como receitas - talvez devido à pouca participação dos mesmos na elaboração destas propostas. Tal visão de currículo vai de encontro às próprias orientações oficiais que valorizam o ensino a partir do contexto e do conhecimento discente, o que é relevante para a abordagem da problemática ambiental.

A idéia de currículo englobando temas referentes à ciência e tecnologia, apesar de restrita - uma vez que colocada sob a ótica de esvaziamento do "conteúdo" por alguns docentes - não deixa de ser um avanço: "falar em poluição, falar em lixo, falar em taxa medicinal, em biotecnologia é falar em vida, não precisa ter matéria, tem que acabar com isso, pedir matéria, pedir matéria, porque cai no vestibular" $[\mathbf{K}]$. Esse pensar se aproxima da perspectiva da abordagem temática, onde o ponto de partida para a estruturação do currículo está nos problemas relevantes, na ótica de suas implicações na sociedade, não obstante haver nessa abordagem a necessidade da conceituação científica para melhor compreensão das problemáticas delimitadas ${ }^{18}$.

A acomodação a uma visão curricular estagnada e tradicional veio freqüentemente justificada por algum problema de ordem operacional ou ideológica. Motivos estes que estariam dificultando ou impedindo a realização de algo diferente. Todavia, mesmo sem negar a influência desses aspectos levantados, reafirma-se que essa inclinação em remeter limitações a outros, mescla-se a dificuldades relativas a sua própria formação profissional.

Parte dos investigados reconheceu "lacunas" no processo de formação profissional que contribuem negativamente para a abordagem de problemas ambientais em sala de aula, principalmente as lacunas de natureza pedagógica, embora tacitamente também podemos evidenciar lacunas no conhecimento disciplinar específico. O relato abaixo dá mostras das dificuldades oriundas da formação dos professores e alguma receptividade a mudanças:

[...] a consciência de uma cidadania, a consciência de uma vida melhor [...] eu não tive isso enquanto escola. Eu gostaria de ter uma formação específica para isso, porque às vezes a gente falha. [...] a gente não planeja isso no dia a dia no planejamento escolar [K].

Esta dificuldade relatada que se encontra em consonância com o discurso de outros professores pode ser uma das heranças dos cursos de formação inicial de professores orientados pela racionalidade técnica. O que não é raro encontrar ainda nos dias de hoje, mesmo existindo políticas públicas para transformação deste quadro. Nos cursos conduzidos pela racionalidade técnica, geralmente os licenciados estudam 3 anos de disciplinas de conteúdo específico e 1 ano (o último) de formação pedagógica ${ }^{40}$.

Noutra fala, as necessidades para que hajam mudanças profissionais é remetida à falta de "material, além do livro didático [...] a questão de vir alguém dar uma palestra sobre isso aí [...]. A própria Secretaria de Educação [...] a própria Universidade" [M], revelando uma compreensão de que suas dificuldades de atuação profissional podem ser superadas com algum apoio externo (vindo do Outro), seja através de material didático ou de instituições públicas formadoras de professores.

Também foram explicitadas dificuldades de aplicação conceitual que possivelmente são oriundas da formação inicial do professor: "olha, inseria ali o gás carbônico, as queimadas, os elementos químicos, a poluição da natureza, porque isso aí aumenta o gás carbônico à camada de ozônio" [F]. Essa questão também necessita ser tratada com maior atenção nos cursos de licenciatura em química. Schnetzler ${ }^{13}$ discute que não é somente a limitação quanto ao conhecimento pedagógico que acompanha o professor de química desde a formação inicial, mas, igualmente o conhecimento químico, implícito na fala do professor quando o mesmo relaciona o aumento do aquecimento global (aumento de $\mathrm{CO}_{2}$ ) ao problema da camada de ozônio. A autora argumenta que tais aspectos tornam os licenciandos presas fáceis dos livros didáticos de química.

Evidentemente, diferentes fatores concorrem para dificultar mudanças significativas almejadas à educação brasileira, e dentre estes estão as condições pedagógicas para o desenvolvimento da ação docente. Isso é um fato amplamente reconhecido que, no entanto, pouco tem sido alterado. Quando a tais fatores se somam questões de natureza epistêmica - como a da concepção de ciência e de meio ambiente - as mudanças significativas são ainda mais dificultadas, e é isso que se pode recolher das manifestações dos professores entrevistados quando se referem aos seus problemas no dia a dia escolar.

\section{CONSIDERAÇÕES FINAIS}

Mesmo os professores conhecendo algo sobre a Química Verde (65\% dos entrevistados disseram que já ouviram falar sobre ela) ou reconhecendo a importância da relação entre a Química e os problemas ambientais, apenas oito professores entrevistados indicaram trabalhar com temas em sala de aula, destes somente um afirma não trabalhar com temas relacionados ao meio ambiente. Desse modo, depreendeu-se da análise dos dados uma forte prevalência de um ensino de Química baseado puramente na transmissão de conteúdos conceituais. Ainda que em muitos casos os professores quando trabalham com informações, exemplos ou questões ligadas ao meio ambiente indicaram preocupação e interesse com o assunto, incorporando alguns argumentos éticos e políticos ao seu discurso didático. Talvez no imaginário docente, a importância da preservação do meio ambiente esteja associada somente a uma questão individual e a um comportamento ético e atitudinal das pessoas visando garantir a sobrevivência humana.

Foi talvez por estes motivos que os treze professores que expressaram realizar uma prática pedagógica tradicional compuseram a maior parte do grupo que representou a compreensão de meio ambiente caracterizada como naturalista e racional. A visão naturalista entre os professores pode ter como conseqüência a idéia 
de que a educação se reduz à função de adaptar os indivíduos a um mundo pré-determinado pelos processos naturais, reforçando a idéia de que o trabalho com temas ambientais em aulas de química deva ter como principal função o ensino de atitudes e valores. E ainda que se considere um avanço tais abordagens, como já afirmamos, elas são insuficientes para tratar da complexidade e urgência da questão ambiental e sua relação com a Química, garantindo nesse processo a apropriação dos conhecimentos científicos/químicos próprios dessa etapa de escolarização.

Não obstante, diante dessa forte característica do grupo pesquisado se destaca o relato de um professor entrevistado que apresentou uma visão que supera as concepções antropocêntricas, acentuando a presença da espécie humana como parte do meio ambiente. $\mathrm{E}$, neste caso, mesmo frente às dificuldades de organização pedagógica e de formação profissional específica, o enfoque dado pelo professor ao tratamento de temas relacionados ao meio ambiente trouxe aproximações a alguns princípios defendidos pela QV.

Foram fortes as manifestações dos entrevistados sobre os problemas relacionados à falta de condições pedagógicas para desenvolverem seus trabalhos (mesmo para aquelas práticas mais tradicionais), aspecto que, concordamos, dificultam as mudanças e a adoção de novas propostas de ensino.

Nesse sentido, há que se ressaltar a falta de sintonia entre a formação continuada dos professores entrevistados e o conhecimento ou a adoção por parte deles de temas mais contemporâneos no ensino de Química, a exemplo da Química Verde, da Química Ambiental e da própria Educação Ambiental. Emergiu nas falas que os cursos de formação inicial e continuada trabalham pouquíssimo a preparação dos educadores para a adoção da perspectiva de organização curricular baseada em temas. Fica evidente a dificuldade que tinham em diferenciar temas, conteúdos e conceitos, e quanto os mesmos estão ainda presos à abordagem puramente conceitual, dado que vinculam exclusivamente um tema a um tópico ou a um determinado conceito químico.

Parece-nos que um tratamento mais significativo e articulado das temáticas ambientais nos currículos dos cursos de Licenciatura, por exemplo, através dos estudos dos princípios da QV e da Química Ambiental, poderia trazer à formação dos educadores os elementos tecno-científicos, éticos e culturais mais significativos sobre a relação entre os problemas ambientais e sua associação com as atividades químicas. Isso poderia ser feito discutindo, por exemplo, aspectos ligados à geração dos problemas ambientais, às alternativas de síntese e também a possíveis contribuições para solucionar tais problemas; perpassando todos os momentos formativos desde a alfabetização científica até a profissionalização. Argumentamos que a introdução da QV em cursos de formação inicial e continuada não deveria ser considerada com uma nova área da química, mas sim incorporar, transversalmente nas áreas clássicas da química, os princípios por ela trabalhados ou revigorados, e internacionalmente reconhecidos. Considera-se que seus princípios têm características epistêmicas e pedagógicas e, portanto, deveriam estar presentes nos processos educativos gerais da educação científica, incluindo a formação dos químicos, licenciados e bacharéis.

Defende-se, portanto, uma formação científica conduzida numa perspectiva CTS, associada tanto a processos didático-metodológicos concebidos na contextualização problematizadora e dialógica, como associada à perspectiva da QV. É necessário ir além de uma educação de valores e atitudes individuais, (muito presentes na Educação Ambiental), alicerçando-a fortemente no domínio de conhecimentos científicos.

Por outro lado, é recomendável que as pesquisas em educação química estejam atentas aos princípios da QV, considerando que a expansão dessa área no meio acadêmico pode contribuir para a formação de profissionais mais responsáveis e tecnicamente capazes na definição de processos químicos que incorporem a variável ambiental. Acreditamos que a incorporação dessa variável pode abrir novos caminhos pedagógicos nos processos de formação de todos os profissionais da química, na medida que as situações de contextos - no sentido amplo - deverão ser trabalhadas.

Por fim, a penetração da QV em nosso meio implica realizarmos leituras mais amplas e profundas sobre suas contribuições, considerando que esta já vem apontando algumas redefinições à Ciência Química. Acreditamos ainda que, ao apoiar sua difusão em ambientes educativos, poder-se-ia estabelecer discussão acerca das compreensões naturalistas e antropocêntricas de meio ambiente, ainda muito fortemente presentes em nossa formação científica.

\section{AGRADECIMENTOS}

Ao CNPq pelo apoio financeiro, aos professores de Química da rede pública estadual de ensino de Santa Catarina e à Secretaria Estadual de Educação, Ciência e Tecnologia do Estado de Santa Catarina.

\section{REFERÊNCIAS}

1. Santos, W. L. P.; Schnetzler, R. P.; Educação em Química: compromisso para cidadania, Unijuí: Ijuí, 1997.

2. Santos, W. L. P.; Tese de Doutorado, Universidade Federal de Minas Gerais, Brasil, 2002.

3. Brasil. Ministério da Educação e do Desporto. Secretaria de Ensino Médio e Tecnológico; Parâmetros Curriculares Nacionais: ensino médio, Brasília, 1999.

4. Brasil. Ministério da Educação e do Desporto. Secretaria de Ensino Médio e Tecnológico; PCN+ ensino médio: orientações curriculares complementares aos Parâmetros Curriculares Nacionais. Ciências da Natureza Matemática e suas Tecnologias, Brasília, 2002.

5. Carvalho, A. M. P.; Gil-Perez, D.; Formação de professores de ciências: tendências e inovações, Cortez: São Paulo, 1993.

6. Vilches, A.; Gil, D.; Construyamos un futuro sostenible: diálogos de supervivencia, Cambridge University Press: Madrid, 2003.

7. Leal, A. L.; Dissertação de Mestrado, Universidade Federal de Santa Catarina, Brasil, 2002.

8. http://habitat.aq.upm.es/cs/p2/a004.html, acessada em Janeiro 2006.

9. http://academic.Scranton.edu.faculty/CANNMI/dreyfusmodules.html, acessada em Dezembro 2004.

10. Moradilho, E. F.; Oki, M. C. M.; Quim. Nova 2004, 27, 332.

11. Sanseverino, A. M.; Ciência Hoje 2002, 31, 20.

12. Lenardão, E. J.; Freitag, R. A.; Dabdoub, M. J.; Batista, A. C. F.; Silveira, C. da C.; Quim. Nova 2003, 26, 123.

13. Schnetzler, R. P.; Quim. Nova 2002, 25, Supl. 1, 14.

14. Angotti, J. A. P.; Auth, M.; Ciência \& Educação 2001, 7, 15.

15. Moraes, E. C. Em Tendências da educação ambiental brasileira; Noal, F. O.; Reigota, M.; Barcelos, V. H. L., eds.; Edunisc: Santa Cruz do Sul, 1998, cap. 3.

16. Moraes, E. C.; Anais do IV Encontro Nacional de Educação em Ciências, Bauru, Brasil, 2004.

17. Freire, P.; Pedagogia do Oprimido, $24^{\mathrm{a}}$ ed., Paz e Terra: Rio de Janeiro, 1997.

18. Delizoicov, D.; Angotti, J. A.; Pernambuco, M. M.; Ensino de Ciências: fundamentos e métodos, Cortez: São Paulo, 2002.

19. Gicquel-Loyon, L. J. C.; Costa, R. H. R.; Anais do Sathla Conference, Rio de Janeiro, Brasil, 1998.

20. Matias, W. G.; Costa, R.; Frello, C. P.; Anais do Sathla Conference, Rio de Janeiro, Brasil, 1998.

21. Richardson, R.; Pesquisa Social: métodos e técnicas, $2^{\mathrm{a}}$ ed., Atlas: São Paulo, 1989.

22. Ludke, M. A.; André, M E. D. A.; Pesquisa em educação: abordagens qualitativas, EPU: São Paulo, 1986.

23. Moraes, R.; Ciência \& Educação 2003, 9, 191.

24. Medeiros, M. G. L.; Ciência \& Educação 2002, 8, 71.

25. Tozoni-Reis, M. F. C.; Ciência \& Educação 2002, 8, 83.

26. Altvater, E.; O preço da riqueza, Ed. da UNESP: São Paulo, 1995.

27. Carvalho, I. C. M.; Educação Ambiental: a formação do sujeito ecológico, Cortez: São Paulo, 2004.

28. Maturana, H.; Varela, F.; Santos, J. P.; A árvore do conhecimento: as bases biológicas do entendimento humano, Editorial PSY: Campinas, 1995. 
29. Auler, D.; Tese de Doutorado, Universidade Federal de Santa Catarina, Brasil, 2002

30. Pacey, A.; La cultura de la tecnología, Fondo de Cultura Económico: México, 1990.

31. Canela, M. C.; Rapkiewicz, C. E.; Santos, A. F.; Química Nova na Escola 2003, n $18,37$.

32. Santos, W. L. P.; Mortimer, E. F.; Anais do II Encontro Nacional de Pesquisa em Educação em Ciências, Valinhos, Brasil, 1999.

33. Koepsel, R.; Dissertação de Mestrado, Universidade Federal de Santa Catarina, Brasil, 2003.

34. Freire, P.; Pedagogia da indignação: cartas pedagógicas e outros escritos, Ed. UNESP: São Paulo, 2000
35. http://www.if.ufrgs.br/public/ensino/revista.htm, acessada em Outubro 2006.

36. Gioppo, C.; Scheffer, E. W.O.; Neves, M. C. D.; Educar 1998, 14, 39.

37. Freire, P.; Pedagogia da autonomia: saberes necessários à prática educativa, $12^{a}$ ed., Paz e Terra: São Paulo, 1996.

38. Leal, M. C.; Tese de Doutorado, Universidade Federal de Minas Gerais, Brasil, 2003.

39. Coelho, J. C.; Dissertação de Mestrado, Universidade Federal de Santa Catarina, Brasil, 2005

40. Diniz-Pereira, J. E.; Formação de professores: pesquisa, representações e poder, Autêntica: Belo Horizonte, 2000. 